\title{
Correlation of GSTM1 gene deletion in joint synovial fluid with the recovery of patients undergoing artificial hip replacement
}

\author{
XIANGBO LIN ${ }^{1}$, TAO XU ${ }^{2}$, BIN WU $^{3}$, BING HU $^{4}$ and MING QIN ${ }^{1}$ \\ ${ }^{1}$ Department of Orthopedics, People's Hospital of Rizhao, Rizhao, Shandong 276800; ${ }^{2}$ Department of Orthopedics, \\ Juxian People's Hospital, Rizhao, Shandong 276500; ${ }^{3}$ Department of Orthopedics, Affiliated Hospital of \\ Jining Medical University, Jining, Shandong 272001; ${ }^{4}$ Department of Ultrasound, \\ People's Hospital of Rizhao, Rizhao, Shandong 276800, P.R. China
}

Received October 9, 2017; Accepted July 24, 2018

DOI: 10.3892/etm.2018.6661

\begin{abstract}
The present study was designed to investigate the correlation between glutathione S-transferase M1 (GSTM1) gene polymorphism and the recovery of patients undergoing artificial hip replacement. A total of 241 patients including 149 males (61.8\%) and 92 females (38.9\%) who received artificial hip replacement in People's Hospital of Rizhao between December 2010 and October 2016 were enrolled to serve as the observation group. Patients were divided into two subgroups according to the loss of GSTM1. A total of 80 healthy subjects who udenrwent a physical examination in our hospital at the same period were selected to serve as the control group. The control group included 41 males $(51.25 \%)$ and 39 females (48.75\%). GSTM1 gene genotyping was performed by polymerase chain reaction-restriction fragment length polymorphism (PCR-RFLP). All patients were followed up for 12 months. Clinical data were compared between the deletion and non-deletion groups and the hospitalization time and the length of the use of antibiotics were compared. Deletion rate of GSTM1 gene in the observation group was $67.63 \%$, which was significantly different from that in the healthy control group [odds ratio $(\mathrm{OR})=1.51,95 \%$ confidence interval $(\mathrm{CI}): 1.075-2.023$, $\mathrm{P}<0.05]$. Notably, a significant difference was indicated in the recovery between patients with and without GSTM1 gene deletion after a year discharged from hospital $(\mathrm{P}<0.05)$. There was no significant difference according to sex, age, hypertension, smoking history, leukocyte, hemoglobin, platelet and BMI index between patients in deletion and non-deletion groups $(\mathrm{P}>0.05)$. However, there was a significant difference in the number of patients with diabetes
\end{abstract}

Correspondence to: Dr Bin Wu, Department of Orthopedics, Affiliated Hospital of Jining Medical University, 89 Guhuai Road, Jining, Shandong 272001, P.R. China

E-mail:w2e559@163.com

Key words: GSTM1, artificial hip replacement, synovial fluid, PCR-RFLP, polymorphism between the two groups $(\mathrm{P}<0.05)$. Hospitalization time and the length of antibiotics use were significantly longer in deletion group compared with non-deletion group $(\mathrm{P}<0.05)$. Infection rate in the deletion group was significantly higher than that in the non-deletion group. Results suggested that GSTM1 gene polymorphism may be correlated with recovery of patients undergoing artificial hip replacement, and GSTM1 gene deletion may correlated with poor recovery.

\section{Introduction}

With the growth of aging population, incidence of hip joint disease shows an increasing trend. Artificial hip replacement is a type of reconstructive operation that replaces the partial or integral damaged hip joint by adopting joint prosthesis fabricated by artificial simulation to ameliorate and restore the function of the hip joint, and is one of the major methods in the treatment of joint diseases in recent years (1-3).

Glutathione $\mathrm{S}$ transferases (GSTs) are an important family of phase II metabolic enzymes in the human body, and family members include GSTM1, GSTT1, and GSTP1 $(4,5)$. A previous study (6), showed that GSTs can catalyze the sulfhydryl group of reduced glutathione to react the electrophilic compound to increase their water solubility for excretion, so as to play an important role in detoxification of carcinogens and metabolism of anticancer drugs. Genetic polymorphisms of GSTs can alter enzyme activity, thus increasing the risk of various diseases (6). A previous study (7) has shown that the missing genotypes of GSTM1 and GSTT1 can lead to loss of function of their encoded enzymes. Alteration of A313G (Ile105Val) on exon 5 of GSTP1 (rs1695) results in decreased thermal stability and reduced specific catalytic activity of the encoded protein. Changes in the polymorphisms of the three genes can affect the metabolism of chemotherapeutic drugs by the cells, resulting in differences in the effective plasma concentrations of chemotherapeutic agents, which ultimately leads to differences in efficacy, toxicity, and prognosis of chemotherapy (8). Currently, GSTs gene polymorphism has attracted more and more attentions. Previous studies have shown that glutathione S-transferase M1 (GSTM1) deletion may lead to the occurrence of some malignant tumors, such as lung cancer (9), liver cancer (10), gastric cancer (11) and 
nasopharyngeal carcinoma (12) and other tumors. A previous study (13), has reported that GSTs gene polymorphisms may lead to reduced antioxidant activity of enzymes, leading to increased susceptibility to diabetes. Another study showed that infection rate of diabetic patients is 3 times higher than that of non-diabetic patients after artificial hip replacement (14). However, the correlations between GSTM1 gene deletion and artificial hip replacement are still controversial. Hence, the present study investigated the correlation between GSTM1 gene deletion and recovery of patients undergoing artificial hip replacement.

\section{Materials and methods}

Basic data. A total of 241 patients who received artificial hip replacement in People's Hospital of Rizhao from December 2010 to October 2016 were enrolled to serve as observation group. Those patients included 149 males (61.8\%) and 92 (38.9\%) females, and the mean age was $65 \pm 9.41$ years. Eighty healthy people who at the same period took physical examination in our hospital were selected to serve as control group. Control group included 41 males $(51.25 \%)$ and 39 females (48.75\%). There were no statistically significant differences in sex, age, hypertension, diabetes and smoking history between two groups $(\mathrm{P}>0.05)$ (Table I). Harris scoring (15), which includes seven indexes: Pain (44 points), daily activity (14 points), gait (11 points), walking aid (11 points), walking distance (11 points), deformity (4 points) and the degree of activity (5 points) was performed with a total of 100 points. Four grades were set based on the total scores: 100-90, excellent; 89-80, good; 79-70, fair; <70, poor. All participants and their families signed informed consent. This study was approved by the Ethics Committee of People's Hospital of Rizhao (Shandong, China).

Instrument and reagents. TRIzol reagent and PCR 2X Taq MasterMix kit was purchased from Invitrogen; Thermo Fisher Scientific, Inc. (Waltham, MA, USA). DNA Marker was purchased from Sigma-Aldrich; Merck KGaA (Darmstadt, Germany). Roche light cycle 480 was purchased from Roche Diagnostics (Basel, Switzerland).

Follow-up. Patients were followed up once every month within the first three months after operation, followed by once every three months for nine months. Hospitalization time, the length of the use of antibiotics and the condition of infection were analyzed in deletion group and non-deletion group were recorded. After discharge from hospital, the patient continued to receive antithrombotic therapy, such as oral coumarin or aspirin, and the corresponding training, such as the constriction exercise of the affected limb, the continuous passive exercise, the training of joint motion, walking practice and stairs exercises were used to prevent postoperative complications.

Exclusion and inclusion criteria. Inclusion criteria: Patients received no hormone drug treatments; patients with normal liver and kidney function; patients willing to cooperate with researchers. Exclusion: Patients with rheumatism, rheumatoid arthritis or gonarthritis; patients with mental illness or physical disability; patients who were not willing to receive treatment.

Collection of specimens and extraction of total ribonucleic acid (RNA). Three milliliters synovial fluid was collected and transferred into a centrifuge tube, followed by centrifugation at $2,500 \mathrm{x}$ g at $4^{\circ} \mathrm{C}$ for $10 \mathrm{~min}$. Subsequently, the supernatant was transferred to a Eppendorf (EP) tube and restored at $-80^{\circ} \mathrm{C}$. DNA was extracted according to the instructions of kit, followed by reservation at $-20^{\circ} \mathrm{C}$.

Single nucleotide polymorphism sequencing. GSTM1 genotyping was performed by polymerase chain reaction-restriction fragment length polymorphism (PCR-RFLP) with $\beta$-globin as the endogenous control. Primer sequence of GSTM1 gene were: 5'-TACTCAGAGTTTCTGGGGAAGCGGC-3' (forward) and 5'-ACGGTGGAGGTCAAGGACATCATAG-3' (reverse); Primer sequences of endogenous control $\beta$-globin were: 5'-GAACCCCAGGGTACAGAGAAAGATC-3' (forward) and 5'-GGACGAAGGAAGAGTGTCGGAAG-3' (reverse). PCR reaction system was $25 \mu \mathrm{l}: 2 \mu \mathrm{l}$ DNA template, $0.5 \mathrm{~mol} / \mathrm{l}$ primer, $2 \times 2.0 \mu \mathrm{l}$ deoxy-ribonucleoside triphosphate (dNTP), $2.5 \mu \mathrm{l}$ buffer, $1.5 \mathrm{~mol} / 1 \mathrm{MgCl}_{2}$ and $1.0 \mathrm{IU}$ TaqDNA. PCR reaction conditions were: Pre-denaturation at $94^{\circ} \mathrm{C}$ for $2 \mathrm{~min}$, followed by 35 cycles of $94^{\circ} \mathrm{C}$ for $45 \mathrm{sec}, 55^{\circ} \mathrm{C}$ for $50 \mathrm{sec}$ and $72^{\circ} \mathrm{C}$ for $50 \mathrm{sec}$, and $72^{\circ} \mathrm{C}$ for $5 \mathrm{~min}$. Finally, 10 ul PCR product was subjected to electrophoresis by using $1.5 \%$ agarose gel for $45 \mathrm{~min}$, followed by staining with $1.5 \%$ ethidium bromide (EB).

Statistical analysis. Data obtained in the present study were analyzed by using Statistical Product and Service Solutions (SPSS, Inc., Chicago, IL, USA) v.17.0 statistical software. Enumeration data were compared by Chi-square test. Measurement data were expressed by mean \pm SD. $t$-test was used for the comparisons between deletion and non-deletion groups. $\mathrm{P}<0.05$ was considered to indicate a statistically significant difference.

\section{Results}

PCR amplification results. Multiplex PCR amplification of GSTM1 was carried to obtain products with a length of 298 , 248 and 207 bp. GSTMl (-) genotype only showed a band of 298 bp, while GSTM1 (+) showed two bands after electrophoresis (Fig. 1).

GSTM1 gene polymorphism and recovery of patients undergoing artificial hip replacement. In the present study, there were 241 patients with artificial hip joint replacement. Giscontinuous chi-square test showed that GSTM1 gene deletion type in observation group (67.63\%) was higher than that in control group (41.25\%), suggesting that deletion of GSTM1 gene is related to the poor recovery of patients undergoing artificial hip replacement (OR=1.51, 95\% CI: 1.075-2.023, $\mathrm{P}<0.05$; Table II).

Comparison of clinical data between deletion group and non-deletion group in experimental group. Patients were divided into GSTM1-deletion and non-GSTM1-deletion 
Table I. Basic data of two groups.

\begin{tabular}{|c|c|c|c|c|c|}
\hline Factor & Experimental group (\%) & Control group (\%) & OR $(95 \% \mathrm{CI})$ & $\chi^{2}$ & P-value \\
\hline \multicolumn{6}{|l|}{ Sex } \\
\hline Male & $149(61.8)$ & $41(51.25)$ & $1.51(1.12-4.94)$ & 0.814 & 0.574 \\
\hline Female & $92(38.9)$ & $39(48.75)$ & & & \\
\hline \multicolumn{6}{|l|}{ Age (years) } \\
\hline$\geq 65$ & $107(44.39)$ & $37(46.25)$ & $2.41(1.71-3.44)$ & 6.74 & 0.749 \\
\hline$<60$ & $134(55.61)$ & $43(53.75)$ & & & \\
\hline \multicolumn{6}{|l|}{ Hypertension } \\
\hline Yes & $170(70.53)$ & $33(41.25)$ & & & \\
\hline No & $71(29.47)$ & $47(58.75)$ & & & \\
\hline \multicolumn{6}{|l|}{ Diabetes } \\
\hline Yes & $96(39.83)$ & $29(36.25)$ & $1.88(1.08-2.98)$ & 5.41 & 0.766 \\
\hline No & $145(60.17)$ & $51(63.75)$ & & & \\
\hline \multicolumn{6}{|l|}{ Smoking history } \\
\hline Yes & $162(67.21)$ & $41(51.25)$ & $2.87(1.74-3.04)$ & 10.55 & 0.648 \\
\hline No & $79(32.79)$ & $39(48.75)$ & & & \\
\hline White blood cells $(10 \times 9 / 1)$ & $4.49 \pm 1.5$ & $4.1 \pm 1.7$ & & 1.948 & 0.052 \\
\hline Hemoglobin $(\mathrm{g} / \mathrm{l})$ & $162.5 \pm 26.40$ & $169.6 \pm 33.00$ & & 1.485 & 0.138 \\
\hline Platelets (10x9/1) & $132.0 \pm 25.14$ & $138.0 \pm 25.20$ & & 1.849 & 0.065 \\
\hline BMI index $\left(\mathrm{kg} / \mathrm{m}^{3}\right)$ & $22.51 \pm 1.30$ & $22.78 \pm 1.15$ & & 1.655 & 0.099 \\
\hline
\end{tabular}

Table II. GSTM1 gene polymorphism and recovery of patients undergoing artificial hip replacement.

\begin{tabular}{lcccrr}
\hline Genotype & Experimental group, $\mathrm{n}=241(\%)$ & Control group, $\mathrm{n}=80(\%)$ & OR (95\% CI) & $\chi^{2}$ & P-value \\
\hline GSTM1 & & & & & \\
GSTM1 $(+)$ & $78(32.37)$ & $47(58.75)$ & - & & \\
GSTM1 $(-)$ & $163(67.63)$ & $33(41.25)$ & $1.51(1.075-2.023)$ & 0.743 & $<0.05$ \\
\hline
\end{tabular}

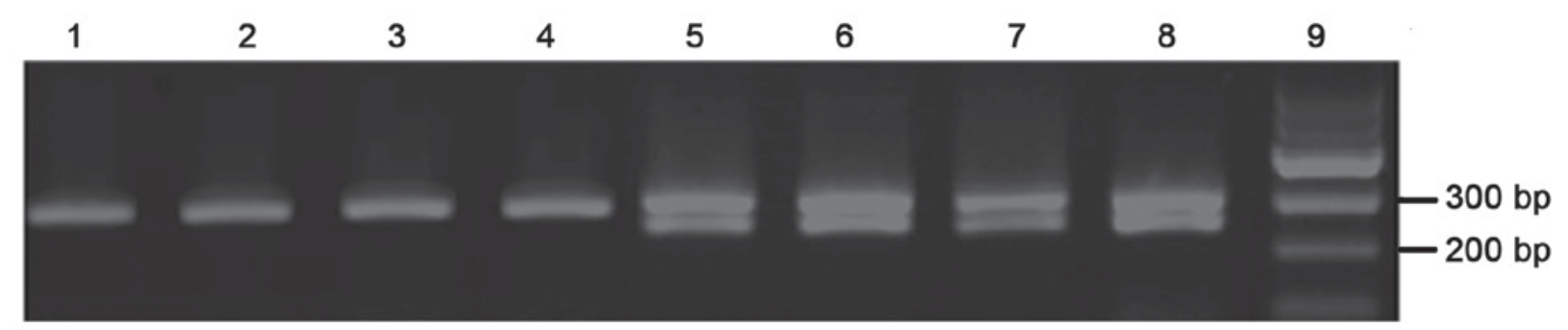

Figure 1. GSTM1 genotyping electrophorogram. Lanes 1,2,3 and 4: GSTMl (-) genotypes; Lanes 5, 6, 7 and 8: GSTM1 (+) genotypes; Lane 9: Marker.

groups. we found that there was no difference in sex, age, hypertension, smoking history, leukocyte, hemoglobin, platelet, and BMI index between patients in deletion and non-deletion groups $(\mathrm{P}>0.05)$, The number of patients with diabetes in GSTM1-deletion was more than that in non-GSTM1-deletion group $(\mathrm{P}<0.05$; Table III).

Prognosis of patients. Hospitalization time and the length of the use of antibiotics were compared between deletion group and non-deletion group. We found that hospitalization time and the length of the use of antibiotics were significantly longer in deletion group than in non-deletion group $(\mathrm{P}<0.05$; Fig. 2$)$. In addition, infection rate of deletion group was significantly higher than that of non-deletion group $(\mathrm{P}<0.05$; Table IV).

Follow-up. Observation group was divided in two groups including deletion group and non-deletion group, and all patients were followed up for 12 months. Harris scoring was performed. No significant differences in Harris scores were found between two groups on the day of discharge $(\mathrm{P}>0.05)$. 
Table III. Comparison of clinical data between deletion group and non-deletion group in experimental group.

\begin{tabular}{|c|c|c|c|c|}
\hline Variables & Deletion $(n=163)$ & Non-deletion $(\mathrm{n}=78)$ & $\mathrm{t}$ & P-value \\
\hline \multicolumn{5}{|l|}{ Sex } \\
\hline Male & 100 & 49 & & \multirow[t]{2}{*}{0.887} \\
\hline Female & 63 & 29 & & \\
\hline \multicolumn{5}{|l|}{ Age (years) } \\
\hline$\geq 65$ & 75 & 32 & & \multirow[t]{2}{*}{0.491} \\
\hline$<65$ & 88 & 46 & & \\
\hline \multicolumn{5}{|l|}{ Hypertension } \\
\hline Yes & 120 & 50 & & \multirow[t]{2}{*}{0.134} \\
\hline No & 43 & 28 & & \\
\hline \multicolumn{5}{|l|}{ Diabetes } \\
\hline Yes & 77 & 19 & & \multirow[t]{2}{*}{0.001} \\
\hline No & 86 & 59 & & \\
\hline \multicolumn{5}{|l|}{ Smoking history } \\
\hline Yes & 115 & 47 & & \multirow[t]{2}{*}{0.142} \\
\hline No & 48 & 31 & & \\
\hline White blood cells $(10 \times 9 / 1)$ & $4.84 \pm 1.76$ & $4.61 \pm 1.24$ & 1.037 & 0.301 \\
\hline Hemoglobin (g/l) & $163.39 \pm 23.87$ & $167.39 \pm 25.75$ & 1.186 & 0.237 \\
\hline Platelet $(10 \times 9 / 1)$ & $126.89 \pm 29.12$ & $134.29 \pm 29.61$ & 1.836 & 0.068 \\
\hline BMI index $\left(\mathrm{kg} / \mathrm{m}^{3}\right)$ & $22.48 \pm 1.84$ & $22.89 \pm 1.06$ & 1.827 & 0.069 \\
\hline
\end{tabular}

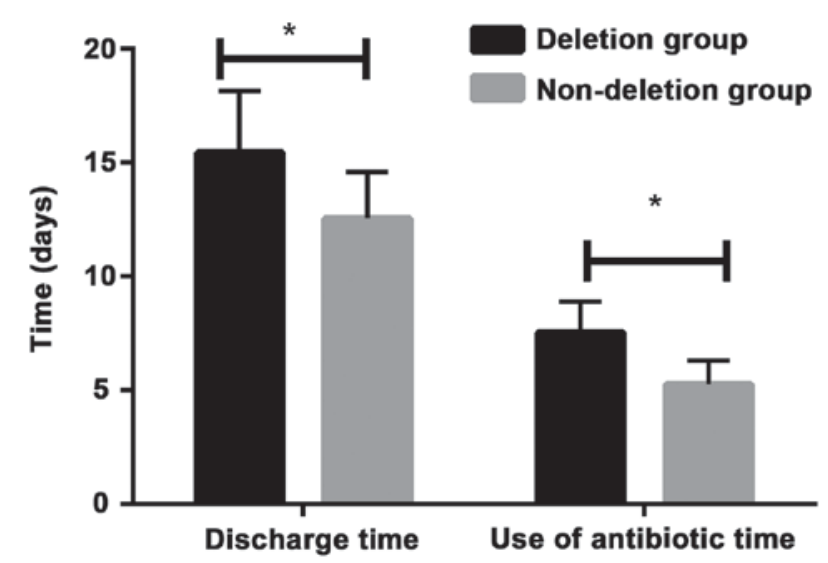

Figure 2. Comparison of hospitalization time and the length of the use of antibiotics between 2 groups. Hospitalization time and the length of the use of antibiotics were significantly longer in deletion group than in non-deletion group. ${ }^{*} \mathrm{P}<0.05$.

Harris scores were significantly lower in deletion group than those in non-deletion group half year $(\mathrm{P}=0.004)$ and one year after discharge $(\mathrm{P}=0.001$; Table $\mathrm{V})$.

\section{Discussion}

In recent years, with the application of biological materials and maturation of surgical techniques, artificial hip replacement technique becomes more and more mature $(16,17)$. At present, postoperative infection is still the main problem of artificial hip replacement, and has a great influence on the recovery of patients (18). Hence, in order to reduce postoperative
Table IV. Prognosis of patients.

\begin{tabular}{lccc}
\hline Groups & Infection & Non-infection & P-value \\
\hline Deletion $(\mathrm{n}=78)$ & $37(47.44)$ & $41(52.56)$ & 0.048 \\
Non-deletion $(\mathrm{n}=163)$ & $55(33.74)$ & $108(66.26)$ & \\
\hline
\end{tabular}

complications caused by artificial hip replacement and improve patient's quality of life, effects of GSTM1 polymorphism on the recovery of patients underwent artificial hip replacement was first investigated in the present study.

As an important phase II metabolic enzyme, GSTM1 is located on the first chromosome, which has detoxificative and cell protective effects to the human body $(19,20)$. A large number of studies reported that (21-23) GSTM1 is associated with the occurrence and prognosis of various types of cancer, but its involvement in artificial hip replacement remains unclear. In the present study, PCR-RFLP technology was adopted to analyze the genotype deletion of GSTM1 gene, so as to study the recovery of patients undergoing artificial hip replacement.

Results of this study indicated that the distribution frequency of deletion type of GSTM1 gene was $41.25 \%$ in control group, which is consistent with the finding in previous study (24). Among 241 patients undergoing artificial hip replacement, there were $163(67.63 \%)$ cases of deletion type of GSTM1 gene. Significant difference in distribution frequency was found between observation group and control group $(\mathrm{OR}=1.51,95 \% \mathrm{CI}: 1.075-2.023, \mathrm{P}<0.05)$, suggesting that deletion of GSTM1 gene is correlated with poor recovery. Studies 
Table V. Comparisons of Harris scores.

\begin{tabular}{lcccr}
\hline Group & $\mathrm{n}$ & Discharge after operation & Half a year after discharge & One year after discharge \\
\hline GSTM1 gene deletion type & 163 & $59.41 \pm 12.88$ & $66.47 \pm 10.57$ & $71.43 \pm 16.94$ \\
GSTM1 gene non-deletion type & 78 & $60.57 \pm 14.38$ & $70.76 \pm 11.67$ & $79.12 \pm 15.51$ \\
t value & & 6.874 & 8.419 & 9.354 \\
P-value & & 0.364 & 0.074 & 0.047 \\
\hline
\end{tabular}

have shown that the absence of the GSTM1 gene may lead to the development of diabetes, and the incidence of infection in patients with diabetes after hip replacement is much higher than normal, delaying recovery and leading to poor prognosi. We compared the clinical data between the deletion group and the non-deletion group. We found that the number patients with diabetes in deletion group were significantly bigger than that in the non-deletion group. This also shows that there is a link between the loss of GSTM1 gene and the prognosis of hip replacement patients. Loss of GSTM1 gene may cause the development of diabetes, and the risk of infection in patients with diabetes after hip replacement is much higher than that in normal people. Therefore, patients were further divided into GSTM1 gene deletion group and GSTM1 gene non-deletion group for follow-up study. Harris score revealed that recovery of patients in GSTM1 gene deletion group was significantly worse compared with that in GSTM1 gene non-deletion group within one year after discharge $(\mathrm{P}<0.05)$, indicating that GSTM1 gene deletion may be a risk factor for the delayed recovery in patients underwent artificial hip replacement. Those results indicate that GSTM1 gene deletion in patients with hip replacement had an impact on prognosis. Life safety and health issues are currently the focus of social attention. Recovery after artificial hip replacement is a slow and systematic process. Individualized treatment and rehabilitation can reduce the occurrence of complications after replacement, thus achieving better recovery effect to improve the quality of life of patients. This study provided references for the prediction of recovery of patients with artificial hip replacement.

It is the first time to make study through combining GSTM1 gene with artificial hip replacement. This study is hoped to provide better service for the recovery of patients and clinical treatment through discussing the relationship between GSTM1 gene and recovery of patients undergoing artificial hip replacement. Also an in-depth discussion will be made according to the results of this study and deeper-seated experiments will be designed according to the guess of influence mechanism in the future. There are also limitations in this study, for example, the short period of the follow-up and small sample size caused by the difficulty in enrolling healthy volunteers, in which may affects the reliability of the results. Future studies with bigger sample size are needed to further confirm the conclusions in the present study.

In conclusion, PCR-RFLP technology is successfully utilized to analyze GSTM1 genotypes in synovial fluid, and the results suggest that GSTM1 gene polymorphism is correlated with recovery of patients undergoing artificial hip replacement. The present study provided references for postoperative rehabilitation of patients undergoing artificial hip replacement.

\section{Acknowledgements}

Not applicable.

\section{Funding}

The present study was supported by the Application Of Accelerated Rehabilitation Surgical Concept In The Perioperative Period Of Hip Arthroplasty (project no. 2016ws0387), the Medical and Health Science And Technology Development Program of Shandong (grant no. 2016WS0327), and the Fund Of Natural Science of Shandong (grant no. ZR2014CQ042).

\section{Availability of data and materials}

The datasets used and/or analyzed during the present study are available from the corresponding author on reasonable request.

\section{Authors' contributions}

XL and TX conceived and designed the study. XL and BH were responsible for the collection and analysis of the data. BW and MQ interpreted the data and drafted the manuscript. XL and BW revised the manuscript critically for important intellectual content. All authors read and approved the final manuscript.

\section{Ethics approval and consent to participate}

The study was approved by the Ethics Committee of People's Hospital of Rizhao (Shandong, China). Signed written informed consent was obtained from the patients and/or guardians.

\section{Patient consent for publication}

Not applicable.

\section{Competing interests}

The authors declare that they have no competing interests.

\section{References}

1. van der Pas SL, Nelissen RGHH and Fiocco M: Patients with staged bilateral total joint arthroplasty in registries: Immortal time bias and methodological options. J Bone Joint Surg Am 99: e82, 2017.

2. Warth LC, Callaghan JJ, Liu SS, Klaassen AL, Goet DD and Johnston RC: Thirty-five-year results after Charnley total hip arthroplasty in patients less than fifty years old: A concise follow-up of previous reports. J Bone Joint Surg Am 96: 1814-1819, 2014. 
3. Cadossi M, Mazzotti A, Baldini N, Giannini S and Savarino L: New couplings, old problems: Is there a role for ceramic-on-metal hip arthroplasty? J Biomed Mater Res B Appl Biomater 104: 204-209, 2016

4. Piacentini S, Polimanti R, Porreca F, Martínez-Labarga C, De Stefano GF and Fuciarelli M: GSTT1 and GSTM1 gene polymorphisms in European and African populations. Mol Biol Rep 38: 1225-1230, 2011.

5. Zhang X,Lin J, Wu X, Lin Z, Ning B, Kadlubar S and Kadlubar FF: Association between GSTM1 copy number, promoter variants and susceptibility to urinary bladder cancer. Int J Mol Epidemiol Genet 3: 228-236, 2012.

6. Wang J, Zou L, Huang S, Lu F, Lang X, Han L, Song Z and $\mathrm{Xu} \mathrm{Z}$ : Genetic polymorphisms of glutathione S-transferase genes GSTM1, GSTT1 and risk of coronary heart disease. Mutagenesis 25: 365-369, 2010.

7. Tang ZH, Zhang C, Cheng P, Sun HM, Jin Y, Chen YJ and Huang F: Glutathione-S-transferase polymorphisms (GSTM1, GSTT1 and GSTP1) and acute leukemia risk in Asians: A meta-analysis. Asian Pac J Cancer Prev 15: 2075-2081, 2014

8. Singh S: Cytoprotective and regulatory functions of glutathione S-transferases in cancer cell proliferation and cell death. Cancer Chemother Pharmacol 75: 1-15, 2015.

9. Tamaki Y, Arai T, Sugimura H, Sasaki T, Honda M, Muroi Y, Matsubara Y, Kanno S, Ishikawa M, Hirasawa N and Hiratsuka M: Association between cancer risk and drug-metabolizing enzyme gene (CYP2A6, CYP2A13, CYP4B1, SULT1A1, GSTM1, and GSTT1) polymorphisms in cases of lung cancer in Japan. Drug Metab Pharmacokinet 26: 516-522, 2011.

10. Wang B, Huang G, Wang D, Li A, Xu Z, Dong R, Zhang D and Zhou W: Null genotypes of GSTM1 and GSTT1 contribute to hepatocellular carcinoma risk: Evidence from an updated meta-analysis. J Hepatol 53: 508-518, 2010.

11. García-González MA, Quintero E, Bujanda L, Nicolás D, Benito R, Strunk M, Santolaria S, Sopeña F, Badía M, Hijona E, et al: Relevance of GSTM1, GSTT1, and GSTP1 gene polymorphisms to gastric cancer susceptibility and phenotype. Mutagenesis 27: 771-777, 2012.

12. Wei Y, Zhou T, Lin H, Sun M, Wang D, Li H and Li B: Significant associations between GSTM1/GSTT1 polymorphisms and nasopharyngeal cancer risk. Tumor Biol 34: 887-894, 2013.

13. Raza S, Abbas S, Ahmad A, Ahmed F, Zaidi Zh and Mahdi F: Association of glutathione-S-transferase (GSTM1 and GSTT1) and FTO gene polymorphisms with type 2 diabetes mellitus cases in Northern India. Balkan J Med Genet 17: 47-54, 2014.

14. Van Ness PH, Peduzzi PN and Quagliarello VJ: Efficacy and effectiveness as aspects of cluster randomized trials with nursing home residents: Methodological insights from a pneumonia prevention trial. Contemp Clin Trials 33: 1124-1131, 2012.

15. Kalairajah Y, Azurza K, Hulme C, Molloy S and Drabu KJ: Health outcome measures in the evaluation of total hip arthroplasties-a comparison between the Harris hip score and the Oxford hip score. J Arthroplasty 20: 1037-1041, 2005.
16. Urquhart DM, Hanna FS, Brennan SL, Wluka AE, Leder K, Cameron PA, Graves SE and Cicuttini FM: Incidence and risk factors for deep surgical site infection after primary total hip arthroplasty: A systematic review. J Arthroplasty 25: 1216-1222 e1-e3, 2010.

17. Bozic KJ, Lau E, Kurtz S, Ong K, Rubash H, Vail TP and Berry DJ: Patient-related risk factors for periprosthetic joint infection and postoperative mortality following total hip arthroplasty in Medicare patients. J Bone Joint Surg Am 94: 794-800, 2012 .

18. Schrama JC, Espehaug B, Hallan G, Engesaeter LB, Furnes O, Havelin LI and Fevang BT: Risk of revision for infection in primary total hip and knee arthroplasty in patients with rheumatoid arthritis compared with osteoarthritis: A prospective, population-based study on 108,786 hip and knee joint arthroplasties from the Norwegian Arthroplasty Register. Arthritis Care Res (Hoboken) 62: 473-479, 2010.

19. Hashemi M, Eskandari-Nasab E, Fazaeli A, Taheri M, Rezaei H, Mashhadi M, Arbabi F, Kaykhaei MA, Jahantigh M and Bahari G: Association between polymorphisms of glutathione S-transferase genes (GSTM1, GSTP1 and GSTT1) and breast cancer risk in a sample Iranian population. Biomark Med 6: 797-803, 2012

20. Wang IJ, Guo YL, Lin TJ, Chen PC and Wu YN: GSTM1, GSTP1, prenatal smoke exposure, and atopic dermatitis. Ann Allergy Asthma Immunol 105: 124-129, 2010.

21. Abdel Rahman HA, Khorshied MM, Elazzamy HH and Khorshid OM: The link between genetic polymorphism of glutathione-S-transferases, GSTM1, and GSTT1 and diffuse large B-cell lymphoma in Egypt. J Cancer Res Clin Oncol 138: 1363-1368, 2012.

22. Borst L, Buchard A, Rosthøj S, Wesolowska A, Wehner PS, Wesenberg F, Dalhoff K and Schmiegelow K: Gene dose effects of GSTM1, GSTT1 and GSTP1 polymorphisms on outcome in childhood acute lymphoblastic leukemia. J Pediatr Hematol Oncol 34: 38-42, 2012.

23. Yang LM, Li XH and Bao CF: Glutathione S-transferase P1 and DNA polymorphisms influence response to chemotherapy and prognosis of bone tumors. Asian Pac J Cancer Prev 13: 5883-5886, 2012

24. Yao ZG, Yong E and Wang HY: The interacted effects between glutathione S-transferase gene polymorphism and smoking in lung cancer. Chinese J Med Guide 14: 185-186 188, 2012 (In Chinese).

This work is licensed under a Creative Commons Attribution-NonCommercial-NoDerivatives 4.0 International (CC BY-NC-ND 4.0) License. 